\title{
Prevalence of hypothyroidism in patients with type 2 diabetes mellitus and hypertension in India: a cross-sectional observational study
}

This article was published in the following Dove Medical Press journal: Diabetes, Metabolic Syndrome and Obesity:Targets and Therapy

\author{
Pradeep Talwalkar \\ Vaishali Deshmukh² \\ Milind Bhole ${ }^{3}$ \\ 'Endocrinology, Talwalkar Diabetes \\ Clinic, Mumbai, India; ${ }^{2}$ Endocrinology, \\ Shree Hospital, Pune, India; ${ }^{3}$ Medical \\ Affairs, Abbott India Ltd, Mumbai, \\ India
}

Purpose: To determine the prevalence of hypothyroidism in patients with type 2 diabetes mellitus (T2DM), hypertension, and both T2DM and hypertension (T2DM + hypertension) in India. Patients and methods: In this cross-sectional observational study, adult patients with an established or newly diagnosed T2DM, hypertension, and T2DM + hypertension who were visiting their physicians for a routine clinical checkup were enrolled across 29 sites in India. All the patient-related data were extracted from their medical records. The prevalence of hypothyroidism was evaluated by thyroid function test (levels of serum free thyroxine, free triiodothyronine, and thyroid-stimulating hormone [TSH]). The proportion of obese and overweight hypothyroid patients and dose of thyroxine in overt and subclinical hypothyroidism $(\mathrm{SCH})$ cases (as per TSH values) were assessed during the study. The results were summarized by descriptive statistics. Results: A total of 1,508 patients (T2DM: 504; hypertension: 501; T2DM + hypertension: 503) were enrolled in the study. The prevalence of hypothyroidism in patients with T2DM, hypertension, and T2DM + hypertension was $24.8 \%, 33.5 \%$, and $28.9 \%$, respectively. The overall prevalence of hypothyroidism in T2DM $(n=1,002)$ and hypertension $(n=1,001)$ was $26.9 \%$ and $31.2 \%$, respectively. The proportion of obese against overweight hypothyroid patients was higher in all indications (T2DM: $16.5 \%$ vs $3.4 \%$; hypertension: $23.8 \%$ vs $5.4 \%$; T2DM + hypertension: $21.5 \%$ vs $3.8 \%$ ). A considerable proportion of patients with $\mathrm{SCH}$ was prescribed thyroxine in T2DM (61.5\%), hypertension (61\%), and T2DM + hypertension $(62.5 \%)$ cases. The most commonly prescribed dose (mean) of thyroxine was 50 and $25 \mu \mathrm{g}$ for overt hypothyroidism and $\mathrm{SCH}$ cases, respectively, in all cohorts.

Conclusion: There is a high ( $>20 \%$ ) prevalence of hypothyroidism in patients with T2DM, hypertension, and T2DM + hypertension. Screening for hypothyroidism should be routinely considered for early diagnosis and effective management.

Keywords: hypertension, hypothyroidism, prevalence, type 2 diabetes mellitus

\section{Introduction}

Hypothyroidism is a decreased functioning of thyroid gland. It can present itself as an overt state of myxedema, end-organ effects, and multisystem failure or subclinical condition with normal levels of thyroxine and triiodothyronine and mildly elevated levels of serum thyrotropin. ${ }^{1}$ The prevalence of hypothyroidism was documented in $\sim 4 \%-5 \%$ of population in the developed world, while in Indian population it was reported in around one in ten adults. ${ }^{2,3}$

Type 2 diabetes mellitus (T2DM) and hypertension have an intersecting underlying pathology with hypothyroidism. Various studies have shown a high prevalence of thyroid
Correspondence: Milind Bhole Abbott India Ltd, Floor 16, Godrej BKC, Plot No. C - 68, BKC, Near MCA Club, Bandra (E), Mumbai - 400 05I, India Tel +9l 829 I465023

Email mbholel70@gmail.com 
disorders (TDs) in patients with T2DM (12\%-23\%) and hypertension (22.5\%). ${ }^{4-13}$ Uncontrolled T2DM affects plasma triiodothyronine (T3) as well as thyroxine (T4) levels. ${ }^{14}$ The possible reasons postulated for an association between diabetes mellitus and hypothyroidism could be genetic, biochemical, or of hormonal origin. ${ }^{15}$ The coexistence of hypothyroidism and type 1 diabetes mellitus (T1DM) may be due to similar autoimmune pathogenesis. Several reports have also indicated a higher prevalence of TD in T2DM patients, with hypothyroidism being the most common disorder. ${ }^{16}$ In patients with hypertension, structural change of vascular tissue and alteration in the autonomic nervous system by thyroid hormone deficiency may increase total peripheral vascular resistance and hypothyroidism. Hypothyroid patients have also shown reduced dopaminergic activity in central nervous system that increases the norepinephrine level, which further contributes to the development of hypertension. ${ }^{17}$

The reported association of hypothyroidism with T2DM and hypertension raises the risk of higher prevalence of hypothyroidism in patients with T2DM and/or hypertension and exacerbation of diabetes- and hypertension-related complications. Hence, screening for hypothyroidism in patients with T2DM and/or hypertension can help in early detection and better management of hypothyroidism. This study was conducted to determine the prevalence of hypothyroidism and the management strategies, including prescription of thyroxine, in Indian patients with T2DM and hypertension.

\section{Patients and methods}

\section{Patients}

This cross-sectional, single-visit, observational study was conducted to assess the prevalence of hypothyroidism in adult patients (aged $\geq 18$ years) with T2DM and/or hypertension (who were already receiving antidiabetic/antihypertensive therapies [established cases] or with fasting plasma glucose [FPG] $\geq 126 \mathrm{mg} / \mathrm{dL}$ or HbA1c $\geq 6.5 \%$ [in newly diagnosed T2DM cases $\left.{ }^{18}\right]$ or with blood pressure [BP] $\geq 140 / 90 \mathrm{mmHg}$ [in hypertension cases ${ }^{19}$ ]) who were visiting their physicians for a routine checkup. The patients were included in the study after obtaining their written informed consent.

The study was conducted from June to September 2017 ( $>3.5$ months) at 29 sites across different geographical regions in India. Patients with T2DM, hypertension, and T2DM + hypertension were recruited in a ratio of $1: 1: 1$. Patients with a history of receiving any drug that may have caused thyroid dysfunction or had an acute illness that affected their thyroid hormone status or subacute thyroiditis with complaints of fever, neck pain, and viral infection or malignancy/a history of a malignancy in the last 5 years or patients on a fixed dose combination of calcium and vitamin D supplement were excluded from the study.

The study protocol and other study-related documents were approved by the Conscience Independent Ethics Committee (Gujarat, India). The study was conducted in full conformity with the principles of the Declaration of Helsinki, International Council for Harmonization-Good Clinical Practices (ICH-GCP) guidelines, Indian Council of Medical Research, Indian GCP guidelines, and as per the approved protocol.

\section{Data collection}

After getting permission from the hospital authorities, the patient data were collected from their hospital medical records. The patient data included their demographics and anthropometric characteristics, medical/surgical/family history, vital measurements, details of T2DM and hypertension, including duration of disease, and latest glycemic indicator values (FPG, postprandial glucose, HbA1c). The laboratory data (if available), including kidney function tests, liver function tests, and serum calcium, were also noted.

\section{Laboratory assessment}

The blood sample was collected from each patient for thyroid function tests (fT3, free thyroxine [fT4], thyroid-stimulating hormone [TSH], and thyroid peroxidase antibody [antiTPO]). The levels of fT3, fT4, serum TSH, and anti-TPO antibody were estimated from the serum of patients using chemiluminescent microparticle immunoassay technology. All the data were captured in the electronic case report form by the delegated study personnel.

\section{Study-related definitions}

\section{Overt hypothyroidism}

A patient was classified to have overt hypothyroidism if the level of TSH was $>4.50 \mu \mathrm{IU} / \mathrm{mL}$, fT $4<0.8 \mathrm{ng} / \mathrm{dL}$, and fT3 $<1.4 \mathrm{pg} / \mathrm{mL} .^{20}$

\section{Subclinical hypothyroidism (SCH)}

A patient was classified to have $\mathrm{SCH}$ if the level of TSH was $>4.50 \mu \mathrm{IU} / \mathrm{mL}$, fT4 was $0.8-1.8 \mathrm{ng} / \mathrm{dL}$, and $\mathrm{fT} 3$ was $1.4-4.4 \mathrm{pg} / \mathrm{mL}^{20}$

\section{Overweight}

A patient was said to be overweight if BMI was $\geq 23$ and $<25 \mathrm{~kg} / \mathrm{m}^{2} .^{21}$ 


\section{Obese}

A patient was said to be obese if BMI was $\geq 25 \mathrm{~kg} / \mathrm{m}^{2} .^{21}$

\section{Study outcomes}

The primary study outcome was the proportion of patients with hypothyroidism (including overt and subclinical) in T2DM, hypertension, and T2DM + hypertension cases.

The secondary outcome measures of interest were the proportion of overweight and obese hypothyroid patients; dose of thyroxine prescribed to patients with overt hypothyroidism and $\mathrm{SCH}$ as per TSH values.

\section{Statistical analysis}

Approximately 1,500 patients, including 500 patients each with T2DM, hypertension, and T2DM + hypertension, were planned to be enrolled into the study, assuming a 10\% dropout rate. The descriptive statistics were used to analyze the study results. The continuous variables were presented as mean \pm $\mathrm{SD}$ and the categorical variables as frequencies and percentages. All the statistical analyses were performed using SAS software version 9.4.

\section{Results}

The data were collected from 1,508 patients (T2DM: 504; hypertension: 501; T2DM + hypertension: 503). Of these, 1,501 (99.5\%) patients (T2DM: 500; hypertension: 499; T2DM + hypertension: 502) completed the study (Figure 1).

\section{Anthropometric, clinical, and laboratory data}

Table 1 summarizes the anthropometric, clinical features, and laboratory profile of patients enrolled in the study. In the overall population, $792(52.5 \%)$ were females and 716 $(47.5 \%)$ were males. The mean age of the overall population was $52.9 \pm 12.5$ years. A higher proportion of the patients were graduates or postgraduates $(45.4 \%)$ and obese $(65.3 \%)$.

A total of 84 (8.3\%) patients with T2DM and $59(5.9 \%)$ patients with hypertension had complications due to their respective conditions. The most common complication due to T2DM and hypertension was diabetic neuropathy (44/84, $52.4 \%)$ and renal disease $(31 / 59,52.5 \%)$, respectively.

A total of 282 (18.8\%) patients (T2DM: 86; hypertension: 109; T2DM + hypertension: 87 ) had a history of hypothyroidism. More than $35 \%$ of the patients had a family history of T2DM, hypertension, or thyroid disease (T2DM: 41.5\%; hypertension: $35.7 \%$; T2DM + hypertension: $48.1 \%$ ).

The levels of fT3, fT4, TSH, and glycemic indicators were similar across the indications. Positive anti-TPO was found in 185 (42.4\%) patients, including $55(44.4 \%)$ patients with T2DM, 80 (47.9\%) patients with hypertension, and 50 (34.5\%) patients with T2DM + hypertension.

\section{Prevalence of hypothyroidism}

A total of 436/1,501 (29.0\%) patients had hypothyroidism (established [old] cases: 282; new cases: 154), of which 124

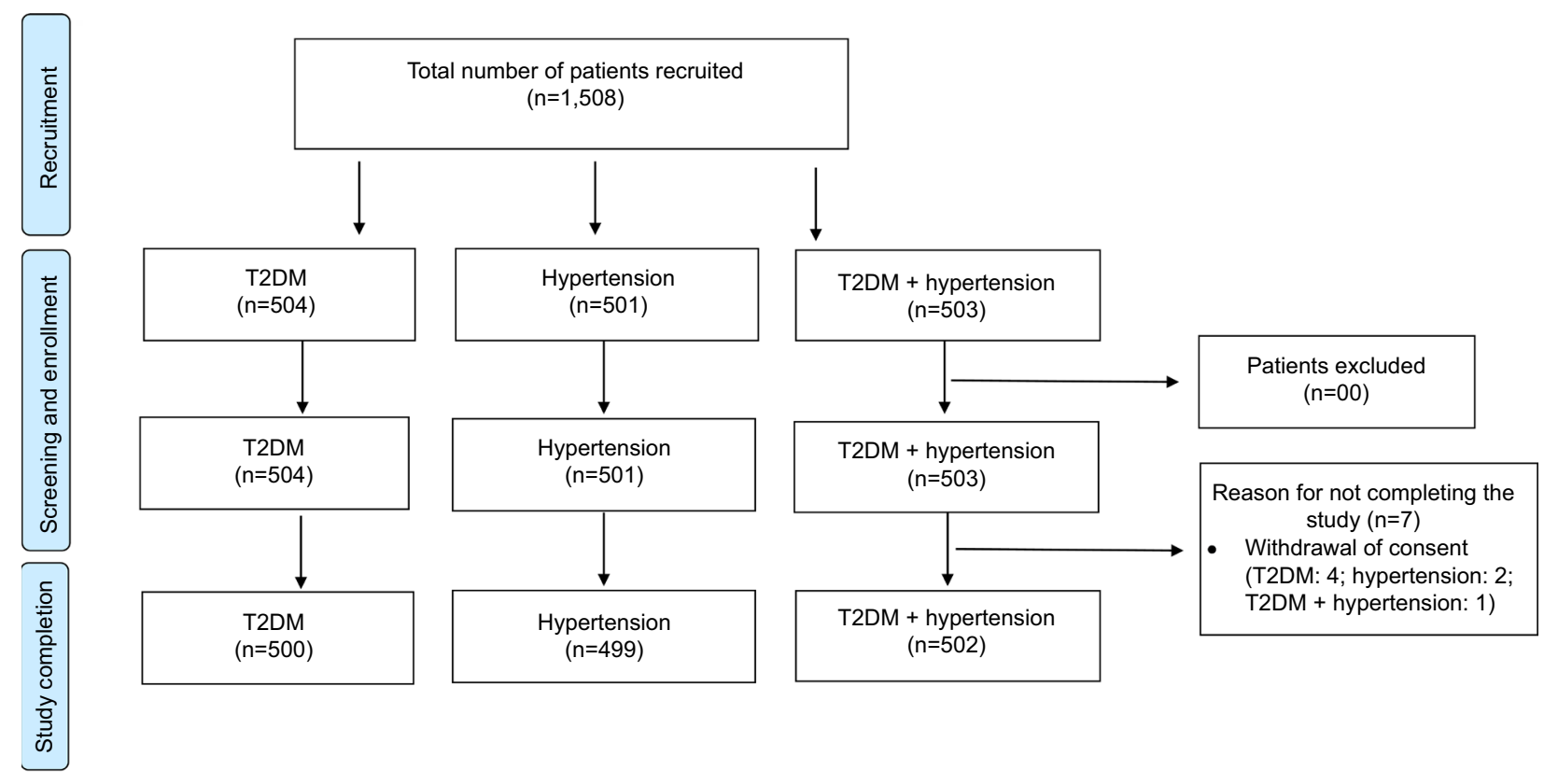

Figure I Study flowchart.

Abbreviation: T2DM, type 2 diabetes mellitus. 
Table I Anthropometric, clinical, and laboratory profile

\begin{tabular}{|c|c|c|c|c|}
\hline Parameters & $\begin{array}{l}\text { T2DM } \\
(n=504)\end{array}$ & $\begin{array}{l}\text { Hypertension } \\
(n=50 I)\end{array}$ & $\begin{array}{l}\text { T2DM + hypertension } \\
(n=503)\end{array}$ & $\begin{array}{l}\text { Overall } \\
(N=1,508)\end{array}$ \\
\hline Age (years), mean \pm SD & $50.7 \pm 12.18$ & $51.6 \pm 13.58$ & $56.4 \pm 10.82$ & $52.9 \pm 12.49$ \\
\hline Weight $(\mathrm{kg})$, mean \pm SD & $69.0 \pm 11.90$ & $70.7 \pm 13.37$ & $71.8 \pm 12.48$ & $70.5 \pm 12.64$ \\
\hline Height $(m)$, mean \pm SD & $1.6 \pm 0.08$ & $1.6 \pm 0.09$ & $1.6 \pm 0.09$ & $1.6 \pm 0.09$ \\
\hline Waist $(\mathrm{cm})$, mean $\pm S D$ & $87.0 \pm 19.03$ & $88.7 \pm 16.63$ & $89.7 \pm 16.42$ & $88.5 \pm 17.43$ \\
\hline Female:male, n (\%) & $240(47.6): 264(52.4)$ & $283(56.5): 218(43.5)$ & $269(53.5): 234(46.5)$ & $792(52.5): 716(47.5)$ \\
\hline Mean BMI $\left(\mathrm{kg} / \mathrm{m}^{2}\right)$, mean $\pm \mathrm{SD}$ & $26.3 \pm 4.24$ & $27.1 \pm 4.60$ & $27.4 \pm 4.54$ & $26.9 \pm 4.49$ \\
\hline \multicolumn{5}{|l|}{ BMI categories, $\mathrm{n}(\%)$} \\
\hline Normal $\left(18.5-22.9 \mathrm{~kg} / \mathrm{m}^{2}\right)$ & $97(19.2)$ & $73(14.6)$ & $70(13.92)$ & $240(15.9)$ \\
\hline Obese $\left(\geq 25 \mathrm{~kg} / \mathrm{m}^{2}\right)$ & $303(60.1)$ & $333(66.5)$ & $349(69.4)$ & $985(65.3)$ \\
\hline Overweight $\left(\geq 23\right.$ and $\left.<25 \mathrm{~kg} / \mathrm{m}^{2}\right)$ & $88(17.5)$ & $86(17.2)$ & $78(15.5)$ & $252(16.7)$ \\
\hline Underweight $\left(<18.5 \mathrm{~kg} / \mathrm{m}^{2}\right)$ & $16(3.2)$ & $9(1.8)$ & $6(1.2)$ & $3 I(2.1)$ \\
\hline \multicolumn{5}{|l|}{ Clinical features } \\
\hline Duration (years), mean \pm SD & $8.3 \pm 6.90$ & $6.8 \pm 5.87$ & - & - \\
\hline Age at diagnosis (years), mean $\pm S D$ & $45.3 \pm 10.31$ & $47.3 \pm 11.20$ & - & - \\
\hline Patients having any complications, $\mathrm{n}(\%)$ & $84(8.3)$ & $59(5.9)$ & & \\
\hline \multicolumn{5}{|l|}{ TPO Ab positivitya, n (\%) } \\
\hline Overt hypothyroidism & $4 I(4 I .8)$ & $65(5 \mid .6)$ & $38(33.6)$ & $144(42.7)$ \\
\hline Subclinical hypothyroidism & $14(53.8)$ & $15(36.6)$ & $12(37.5)$ & $4 \mid(4 I .4)$ \\
\hline Overt + subclinical hypothyroidism & $55(44.4)$ & $80(47.9)$ & $50(34.5)$ & $185(42.4)$ \\
\hline \multicolumn{5}{|l|}{ Vital parameters, mean \pm SD } \\
\hline Pulse rate (bpm) & $77.4 \pm 6.88$ & $76.1 \pm 7.27$ & $77.7 \pm 9.38$ & $77.0 \pm 7.94$ \\
\hline Systolic blood pressure $(\mathrm{mmHg})$ & $124.2 \pm 9.88$ & $|34.8 \pm| 4.6 \mid$ & $133.9 \pm 16.38$ & $131.0 \pm 14.69$ \\
\hline Diastolic blood pressure $(\mathrm{mmHg})$ & $79.8 \pm 6.23$ & $86.5 \pm 7.60$ & $83.4 \pm 9.31$ & $83.3 \pm 8.28$ \\
\hline Respiratory rate (breaths/min) & $17.1 \pm 1.79$ & $17.7 \pm 197$ & $17.4 \pm 1.84$ & $17.4 \pm 1.88$ \\
\hline \multicolumn{5}{|l|}{ Laboratory parameters } \\
\hline \multicolumn{5}{|l|}{ Thyroid function test, $n$; mean \pm SD } \\
\hline $\mathrm{fT} 3(\mathrm{pg} / \mathrm{mL})$ & $500 ; 3.7 \pm 10.69$ & 499; $3.4 \pm 8.91$ & $50 I ; 3.3 \pm 9.23$ & $1500 ; 3.5 \pm 9.64$ \\
\hline fT4 (ng/dL) & $500 ; 1.1 \pm 0.68$ & 499; $1.2 \pm 0.80$ & $50 \mathrm{I} ; \mathrm{I} .2 \pm 0.77$ & $150 \mid ; I . I \pm 0.75$ \\
\hline $\mathrm{TSH}(\mu \mathrm{lU} / \mathrm{mL})$ & $500 ; 3.3 \pm 7.04$ & $499 ; 4.0 \pm 11.37$ & $502 ; 3.1 \pm 6.93$ & $1501 ; 3.5 \pm 8.6$ \\
\hline \multicolumn{5}{|l|}{ Glycemic indicators test, $\mathrm{n}$; mean \pm SD } \\
\hline FPG (mg/dL) & $206 ; 150.1 \pm 69.49$ & $25 ; 94.0 \pm 12.69$ & $219 ; 130.6 \pm 45.43$ & $450 ; 137.5 \pm 58.45$ \\
\hline PPG (mg/dL) & $194 ; 216.3 \pm 100.83$ & $15 ; 113.6 \pm 22.18$ & $213 ; 189.3 \pm 69.96$ & $422 ; 199.0 \pm 87.11$ \\
\hline $\mathrm{HbAlc}(\%)$ & $142 ; 8.5 \pm 2.25$ & $8 ; 5.9 \pm 0.37$ & $131 ; 7.9 \pm 1.89$ & $28 I ; 8.1 \pm 2.11$ \\
\hline
\end{tabular}

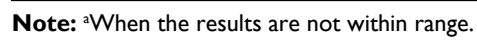

Abbreviations: BMI, body mass index; FPG, fasting plasma glucose, fT3, free triiodothyronine; fT4, free thyroxine; PPG, postprandial glucose; T2DM, type two diabetes mellitus; TPO Ab, thyroid peroxidase antibody; TSH, thyroid-stimulating hormone.

(24.8\%) cases were reported in patients with T2DM, 167 $(33.5 \%)$ in patients with hypertension, and $145(28.9 \%)$ in patients with T2DM + hypertension. The overall prevalence of hypothyroidism in patients with T2DM and hypertension was found to be $26.9 \%(269 / 1,002)$ and $31.2 \%(312 / 1,001)$, respectively.

Of 436 patients with hypothyroidism, $337(77.3 \%)$ had overt hypothyroidism and 99 (22.7\%) had SCH. Among new hypothyroid cases, $\mathrm{SCH}$ were more prevalent than that of overt hypothyroidism across all indications (Table 2).

Of all patients with hypothyroidism, 310 (20.6\%) were obese and $63(4.2 \%)$ were overweight. The proportion of obese and overweight hypothyroid cases was higher in patient with hypertension compared with those with T2DM and T2DM + hypertension (overweight: T2DM: 3.4\%, hypertension: $5.4 \%$, T2DM + hypertension: $3.8 \%$; obese: T2DM: 16.5\%, hypertension: $23.8 \%$, T2DM + hypertension: $21.5 \%$ ).

\section{Thyroxine treatment}

More than $50 \%$ of the hypothyroid patients with T2DM, hypertension, and T2DM + hypertension was prescribed thyroxine. A considerable proportion of patients with $\mathrm{SCH}$ was prescribed thyroxine in patients with T2DM (16 [61.5\%]), hypertension (25 [61.0\%]), and T2DM + hypertension (20 [62.5\%]). The most commonly prescribed mean dose of thyroxine was 50 and $25 \mu \mathrm{g}$ in overt hypothyroidism and $\mathrm{SCH}$ 
Table 2 Prevalence of hypothyroidism (old and new) in newly and previously diagnosed patients

\begin{tabular}{|c|c|c|c|c|c|c|c|c|c|c|}
\hline \multirow[t]{3}{*}{ Type of cases } & \multicolumn{10}{|c|}{$\begin{array}{l}\text { Number (\%) of patients with classification of hypothyroidism in old and newly diagnosed cases across } \\
\text { different clinical conditions }\end{array}$} \\
\hline & \multicolumn{3}{|c|}{ T2DM $(n=500)$} & \multicolumn{3}{|c|}{ Hypertension $(n=499)$} & \multicolumn{3}{|c|}{$\begin{array}{l}\text { T2DM + hypertension } \\
(n=502)\end{array}$} & \multirow[t]{2}{*}{$\begin{array}{l}\text { Overall } \\
(N=I, 50 I)\end{array}$} \\
\hline & Overt & SCH & Total & Overt & SCH & Total & Overt & SCH & Total & \\
\hline Newly diagnosed cases & $12(2.4)$ & $26(5.2)$ & $38(7.6)$ & $17(3.4)$ & $41(8.2)$ & $58(11.6)$ & $26(5.2)$ & $32(6.4)$ & $58(11.6)$ & $154(10.2)$ \\
\hline Old cases & $86(17.2)$ & - & $86(17.2)$ & $109(21.8)$ & - & $109(21.8)$ & $87(17.3)$ & - & $87(17.3)$ & $282(18.8)$ \\
\hline Overall & $98(19.6)$ & $26(5.2)$ & $124(24.8)$ & $126(25.3)$ & $4 I(8.2)$ & $167(33.5)$ & $113(22.5)$ & $32(6.4)$ & $145(28.9)$ & $436(29.0)$ \\
\hline
\end{tabular}

Abbreviations: $\mathrm{SCH}$, subclinical hypothyroidism; T2DM, type 2 diabetes mellitus.

cases, respectively, across all cohorts (overt: T2DM: 33.3\%, hypertension: $23.9 \%$, T2DM + hypertension: $30.3 \%$; $\mathrm{SCH}$ : T2DM: $56.3 \%$, hypertension: $56.0 \%$, T2DM + hypertension: $75.0 \%)$.

\section{Discussion}

Hypothyroidism, as defined by underactive thyroid gland, has been estimated to affect $\sim 10 \%$ of the Indian population. ${ }^{3}$ Diabetes and hypertension have shown a significant association with hypothyroidism. ${ }^{17,22}$ We undertook this study to determine the prevalence of hypothyroidism in patients with T2DM and hypertension and further explored the management strategies, including thyroxine prescription, at 29 sites in India.

This study clearly reported a high prevalence of hypothyroidism in patients with T2DM (24.8\%), hypertension (33.5\%), and $\mathrm{T} 2 \mathrm{DM}+$ hypertension $(28.9 \%)$ compared with documented prevalence in the existing literature. The published studies have reported hypothyroidism prevalence to be $11 \%-23 \%$ in patients with $\mathrm{T}_{2} \mathrm{DM}^{7-11,16}$ and $18 \%-22.5 \%$ in patients with essential hypertension. ${ }^{13,23}$ The advent of more sensitive and specific TSH assays could be a reason for presumptive diagnosis, thereby higher prevalence of hypothyroidism in our study. In T2DM patients, the higher prevalence of hypothyroidism could be attributed to higher mean glycemic status $(\mathrm{HbA} 1 \mathrm{c}=8.5 \%)$ within the cohort. Studies have shown that the serum T3 levels, basal TSH levels, and TSH response to thyrotropin releasing hormone are strongly influenced by the glycemic control. ${ }^{11}$ Longer duration of diabetes and hypertension along with more elderly and obese patients in our study could also have contributed to higher prevalence of hypothyroidism. A long-standing iodine deficiency in Indian population and several environmental factors like an increase in unregulated use of pesticides, exposure to industrial pollutants including goitrogens, and consumption of unclean drinking water in the past decade may serve as the other causes of hypothyroidism. ${ }^{24}$
Hypothyroidism is usually underreported due to its higher prevalence in rural than in urban areas. In view of this, screening for hypothyroidism has been emphasized in a subset of patients' population who are suffering from conditions that have shown an association with hypothyroidism. A close monitoring and screening of thyroid function are recommended by many societies in T1DM patients. However, the same practice in T2DM patients is less precise. ${ }^{18,25,26}$ Polish Society of Endocrinology and Polish Diabetes Association, British Thyroid Association and Association of Clinical Biochemistry, and Indian Thyroid Society recommend that patients diagnosed with T2DM require thyroid function testing at the time of diagnosis. However, annual testing of thyroid function is not recommended. ${ }^{26-28}$ In addition, the guidelines of major endocrine and diabetes societies are ambiguous with respect to specific screening policy, including the choice of thyroid function tests, frequency of screening, and the intervals between testing in all diabetes patients. Also, American College of Cardiology/American Heart Association Task Force on Clinical Practice Guidelines consider hypothyroidism and hyperthyroidism as two remediable causes of hypertension and recommend TSH testing in evaluation of patients with primary hypertension. ${ }^{29}$ The uncertain recommendations of major societies, excess of medications used due to associated comorbidities, high cost of thyroid profile test, adverse events of medications, poor awareness among patients, limited resources in primary health care, and asymptomatic nature of the disease (in some cases) are few major obstacles for thyroid screening in T2DM and hypertensive population.

An array of physiological aberrations is reported in patients with TD and diabetes mellitus and/or hypertension. Thyroid hormones play an important role in maintaining regular blood glucose, circulating levels of insulin, and counterregulatory hormone like epinephrine. In patients with poorly controlled diabetes, reduced T3 levels have been observed along with impairment of the response of serum 
TSH to thyrotropin releasing hormone stimulation. ${ }^{30}$ Hyperinsulinemia in association with insulin resistance has shown a proliferative effect on thyroid tissue resulting in increased formation of thyroid nodules. ${ }^{31}$ The deficiency of thyroid hormone accelerates the structural changes in vascular tissue and increases the total peripheral resistance. The elevated TSH and thyroid hormone deficit contribute to the development of hypertension by increasing the norepinephrine release by altering the autonomic nervous function and reducing dopaminergic activity in the brain, respectively. ${ }^{17}$

Multiple studies have reported a positive association of BMI with levels of TSH, T3 (total and free), and serum leptin, which could be due to progressive fat accumulation. ${ }^{32-34}$ Fatty individuals have underexpression of TSH receptors on their adipocytes, which further increases the plasma concentration of TSH and fT3. ${ }^{34-37}$ In our study, $20.6 \%$ of the hypothyroid patients were identified as obese and $4.2 \%$ as overweight, further suggesting a direct relationship between BMI and proportion of patients with hypothyroidism.

In this study, among new hypothyroid cases, $\mathrm{SCH}$ was more prevalent than overt hypothyroidism across all cohorts. This may be possibly because $\mathrm{SCH}$ represents an early or initial stage of thyroid disease, which may progress to the chronic condition of overt hypothyroidism, if not appropriately treated. In 2012, Khandelwal and Tandon reported the annual progression of $\mathrm{SCH}$ cases to overt hypothyroidism in $\sim 2 \%-5 \%$ cases. ${ }^{38}$ Hence, a closer monitoring of thyroid function tests along with adjustment of thyroxine doses is imperative in patients with $\mathrm{SCH}$, particularly in high-risk population.

The TSH assay is the best for initially evaluating thyroid function and is the most reliable test for diagnosing primary hypothyroidism in outpatient settings. ${ }^{39,40}$ Patients with TSH levels between 4.5 and $10 \mu \mathrm{U} / \mathrm{mL}$ and normal serum-free T4 levels ( $\mathrm{SCH}$ ) should be carefully evaluated and monitored for changes in their hormone levels. In our study, a considerable proportion of patients with T2DM (54.0\%), hypertension (55.1\%), and T2DM + hypertension (59.3\%) were prescribed thyroxine. A higher proportion of patients with $\mathrm{SCH}$ were prescribed thyroxine in all cohorts. The most common mean dose of thyroxine in overt hypothyroidism and $\mathrm{SCH}$ cases was 50 and $25 \mu \mathrm{g}$, respectively. Our results were supported by another study, which recommended the initial dosage of thyroxine to be $25-50 \mathrm{U}$ in patients with $\mathrm{SCH} .{ }^{41}$ Various randomized clinical trials have also shown daily dose of 25 or $50 \mu \mathrm{g}$ with subsequent dose adjustments to be effective in normalizing the raised serum TSH levels in patients with
$\mathrm{SCH} .{ }^{42,43}$ In another study, a dose of $25 \mu \mathrm{g}$ thyroxine was recommended followed by gradual step-up approach in a patient with stable angina pectoris. ${ }^{44}$ In addition, the clinical practice guideline for hypothyroidism by American Association of Clinical Endocrinologists/American Thyroid Association recommends a dose of thyroxine to be $25-75 \mu \mathrm{g} /$ day, depending on the degree of TSH elevation, in patients with $\mathrm{SCH}$. Further adjustments of thyroxine dose should be based on their clinical response and follow-up TSH values. ${ }^{45}$ Hence, adjusting thyroxine dose in hypothyroid patients facilitates the care and helps in prompt normalizations of TSH levels and improves general well-being.

Our study has few strengths and limitations. The strength being that ours is the first study highlighting the burden of hypothyroidism in patients with T2DM and hypertension and identifying the impact of this comorbidity on the prevalence of hypothyroidism. It can be assumed that patients participating in this study represent the overall population as they are enrolled from 29 sites across different geographical regions all over India. There are few limitations of this study. First, no control group was included to see the viability of results in the studied population. Second, this study was limited in its ability to conclude an association between hypothyroidism with gender, age, and duration of diabetes or hypertension. Third, no test was carried out to measure iodine content in the food samples or urinary iodine excretion for identification of level of iodine content.

Nevertheless, this study provides the first nationwide data on the prevalence of hypothyroidism in patients with T2DM and/or hypertension. However, a longitudinal study needs to be undertaken to ascertain the long-term association between TD and T2DM and/or hypertension and to assess its impact on disease progression to provide stronger evidence of association between T2DM, hypertension, and hypothyroidism.

\section{Conclusion}

This study reports the high prevalence of hypothyroidism in patients with T2DM, hypertension, and T2DM + hypertension. Most of the patients are previously known cases of overt hypothyroidism and are obese. This study further supports the existing literature in reporting the comorbidities among T2DM/hypertension/hypothyroidism and the utility of screening for hypothyroidism in patients with T2DM and/ or hypertension as early diagnosis not only can lead to better management of hypothyroidism but can also be helpful in addressing the complications of diabetes and hypertension, which are shown to be accentuated by hypothyroidism. 


\section{Acknowledgments}

This study was funded by Abbott India Ltd. The authors thank GCE Solutions and Dr Shalini Nair (Abbott) for providing writing and editing assistance in developing this manuscript. These data were presented at the European Congress of Endocrinology (ECE), 19-22 May 2018, as a poster presentation. The poster's abstract was published in Endocrine Abstracts. 2018;56:P1054.

\section{Author contributions}

All authors contributed toward conception and design, data analysis and interpretation, drafting and critically revising the paper, gave final approval of the version to be published, and agree to be accountable for all aspects of the work.

\section{Disclosure}

Dr Talwalkar and Dr Deshmukh received research funding from Abbott India Ltd. Dr Bhole is an employee of Abbott India Ltd. The authors report no other conflicts of interest in this work.

\section{References}

1. Chaker L, Bianco AC, Jonklaas J, Peeters RP. Hypothyroidism. Lancet. 2017;390(10101):1550-1562.

2. Hoogendoorn EH, Hermus AR, de Vegt F, et al. Thyroid function and prevalence of anti-thyroperoxidase antibodies in a population with borderline sufficient iodine intake: influences of age and sex. Clin Chem. 2006;52(1):104-111.

3. Unnikrishnan AG, Kalra S, Sahay RK, Bantwal G, John M, Tewari N. Prevalence of hypothyroidism in adults: an epidemiological study in eight cities of India. Indian J Endocrinol Metab. 2013;17(4):647-652.

4. Papazafiropoulou A, Sotiropoulos A, Kokolaki A, Kardara M, Stamataki P, Pappas S. Prevalence of thyroid dysfunction among Greek type 2 diabetic patients attending an outpatient clinic. J Clin Med Res. 2010;2(2):75.

5. Cai Y, Ren Y, Shi J. Blood pressure levels in patients with subclinical thyroid dysfunction: a meta-analysis of cross-sectional data. Hypertens Res. 2011;34(10):1098-1105.

6. Singh G, Gupta V, Sharma AK, Gupta N. Evaluation of thyroid dysfunction among type 2 diabetic Punjabi population. Adv Biores. 2011;2:3-9

7. Demitrost L, Ranabir S. Thyroid dysfunction in type 2 diabetes mellitus: a retrospective study. Indian J Endocr Metab. 2012;16(Suppl 2):S334-335.

8. Han C, He X, Xia X, et al. Subclinical hypothyroidism and type 2 diabetes: a systematic review and meta-analysis. PLoS One. 2015;10(8):e0135233.

9. Devi MA, Singh NS, Singh LS. Thyroid hormone dysfunction in type 2 diabetic patients in urban areas of Manipur. Int J Pharm Sci Int. 2013;2:7-9.

10. Vikram VB, Kanitkar SA, Tamakuwala KK, et al. Thyroid dysfunction in patients with type 2 diabetes mellitus at tertiary care centre. Nat J Med Res. 2013;3:377-380.

11. Uppal V, Vij C, Bedi GK, Vij A, Banerjee BD. Thyroid disorders in patients of type 2 diabetes mellitus. Indian $J$ Clin Biochem. 2013;28(4):336-341.

12. Khuranaa A, Dhoat P, Jain G. Prevalence of thyroid disorders in patients of type 2 diabetes mellitus. J Indian Acad Clin Med. 2016;17:13.
13. Curnock AL, Dweik RA, Higgins BH, Saadi HF, Arroliga AC. High prevalence of hypothyroidism in patients with primary pulmonary hypertension. Am J Med Sci. 1999;318(5):289-292.

14. Saunders J, Hall SE, Sönksen PH, Sönksen P. Thyroid hormones in insulin requiring diabetes before and after treatment. Diabetologia. 1978;15(1):29-32.

15. Wang $C$. The relationship between type 2 diabetes mellitus and related thyroid diseases. J Diabetes Res. 2013;2013(6):1-9.

16. Kadiyala R, Peter R, Okosieme OE. Thyroid dysfunction in patients with diabetes: clinical implications and screening strategies. Int J Clin Pract. 2010;64(8):1130-1139.

17. Saito I, Ito K, Saruta T. Hypothyroidism as a cause of hypertension. Hypertension. 1983;5(1):112-115.

18. American Diabetes Association. Standards of medical care in diabetes. Introduction. Diabetes Care. 2017;40(Suppl 1):S1-S2.

19. Whelton PK, Carey RM. The 2017 American College of Cardiology/ American Heart Association clinical practice guideline for high blood pressure in adults. JAMA Cardiol. 2018;3(4):352-353.

20. Dayan CM. Interpretation of thyroid function tests. Lancet. 2001;357(9256):619-624.

21. Misra A, Makkar BM, Makkar BM, et al. Consensus statement for diagnosis of obesity, abdominal obesity and the metabolic syndrome for Asian Indians and recommendations for physical activity, medical and surgical management. J Assoc Physicians India. 2009;57: 163-170.

22. Subekti I, Pramono LA, Dewiasty E, Harbuwono DS. Thyroid dysfunction in type 2 diabetes mellitus patients. Acta Med Indones. 2017;49(4):314-323.

23. Turchi F, Ronconi V, di Tizio V, Boscaro M, Giacchetti G. Blood pressure, thyroid-stimulating hormone, and thyroid disease prevalence in primary aldosteronism and essential hypertension. Am J Hypertens. 2011;24(12):1274-1279.

24. Bagcchi S. Hypothyroidism in India: more to be done. Lancet Diabetes Endocrinol. 2014;2(10):778.

25. Baskin HJ, Cobin RH, Duick DS, et al. American Association of clinical endocrinologists medical guidelines for clinical practice for the evaluation and treatment of hyperthyroidism and hypothyroidism. Endocrine Practice. 2002;8(6):457-469.

26. The Association for Clinical Biochemistry; British Thyroid Association; British Thyroid Foundation. UK Guidelines for the Use of Thyroid Function Tests. 2006. Available from: http://www.btf-thyroid.org/images/ documents/tft_guideline_final_version_july_2006.pdf. Accessed October 10, 2018.

27. Sowiński J, Czupryniak L, Milewicza, et al. Polish Society of endocrinology; Polish diabetes association. Recommendations of the Polish Society of endocrinology and Polish diabetes association for the management of thyroid dysfunction in type 1 and type 2 diabetes. Endokrynol Pol. 2013;64:73-77.

28. Jayakumar RV. Hypothyoidism and Diabetes Indian Consensus Statement. New Delhi: Elsevier Relx India Pvt Ltd; 2016.

29. Carey RM, Aronow WS, Whelton PK, et al. ACC/AHA/AAPA/ABC/ ACPM/AGS/APhA/ASH/ASPC/NMA/PCNA guideline for the prevention, detection, evaluation, and management of high blood pressure in adults: a report of the American College of Cardiology/American Heart Association Task Force on clinical practice guidelines. J Am Coll Cardiol. 2017;2018(71):e127-248.

30. Gursoynt NT, Tuncel E, Erturk E, Imamoglu S, Arinik A. The relationship between the glycemic control and the hypothalamus-pituitarythyroid axis in diabetic patients. Turkish J Endocrinol Metabol. 1999;4:163-168.

31. Tsatsoulis A. The role of insulin resistance/hyperinsulinism on the rising trend of thyroid and adrenal nodular disease in the current environment. J Clin Med. 2018;26:E37.

32. Reinehr T, de Sousa G, Andler W. Hyperthyrotropinemia in obese children is reversible after weight loss and is not related to lipids. $J$ Clin Endocrinol Metab. 2006;91(8):3088-3091. 
33. De Pergola G, Ciampolillo A, Paolotti S, Trerotoli P, Giorgino R. Free triiodothyronine and thyroid stimulating hormone are directly associated with waist circumference, independently of insulin resistance, metabolic parameters and blood pressure in overweight and obese women. Clin Endocrinol. 2007;67(2):265-269.

34. Nannipieri M, Cecchetti F, Anselmino M, et al. Expression of thyrotropin and thyroid hormone receptors in adipose tissue of patients with morbid obesity and/or type 2 diabetes: effects of weight loss. Int J Obes (Lond). 2009;33(9):1001-1006.

35. Biondi B, Thyroid BB. Thyroid and obesity: an intriguing relationship. J Clin Endocrinol Metab. 2010;95(8):3614-3617.

36. Knudsen N, Laurberg P, Rasmussen LB, et al. Small differences in thyroid function may be important for body mass index and the occurrence of obesity in the population. J Clin Endocrinol Metab. 2005;90(7): 4019-4024.

37. ReinehrT. Obesity and thyroid function. Mol Cell Endocrinol. 2010;316(2): 165-171.

38. Khandelwal D, Tandon N. Overt and subclinical hypothyroidism: who to treat and how. Drugs. 2012;72(1):17-33.

39. Ladenson PW, Singer PA, Ain KB, et al. American thyroid association guidelines for detection of thyroid dysfunction. Arch Intern Med. 2000;160(11):1573-1575.

40. Baloch Z, Carayon P, Conte-Devolx B, et al. Guidelines Committee, National Academy of clinical biochemistry, laboratory medicine practice guidelines. Laboratory support for the diagnosis and monitoring of thyroid disease. Thyroid. 2003;13:3-126.
41. Adlin V. Subclinical hypothyroidism: deciding when to treat. Am Fam Physician. 1998;57(4):776-780.

42. Jorde R, Waterloo K, Storhaug H, Nyrnes A, Sundsfjord J, Jenssen TG. Neuropsychological function and symptoms in subjects with subclinical hypothyroidism and the effect of thyroxine treatment. J Clin Endocrinol Metab. 2006;91(1):145-153.

43. Razvi S, Ingoe L, Keeka G, Oates C, McMillan C, Weaver JU. The beneficial effect of L-thyroxine on cardiovascular risk factors, endothelial function, and quality of life in subclinical hypothyroidism: randomized, crossover trial. J Clin Endocrinol Metabol. 2007;92(5):1715-1723.

44. Roos A, Linn-Rasker SP, van Domburg RT, Tijssen JP, Berghout A. The starting dose of levothyroxine in primary hypothyroidism treatment: a prospective, randomized, double-blind trial. Arch Intern Med. 2005;165(15):1714-1720.

45. Garber JR, Cobin RH, Gharib H, et al. American Association of clinical endocrinologists and American thyroid association Taskforce on hypothyroidism in adults. Clinical practice guidelines for hypothyroidism in adults: cosponsored by the American Association of clinical endocrinologists and the American thyroid association. Endocr Pract. 2012;18:988-1028

\section{Publish your work in this journal}

Diabetes, Metabolic Syndrome and Obesity: Targets and Therapy is an international, peer-reviewed open-access journal committed to the rapid publication of the latest laboratory and clinical findings in the fields of diabetes, metabolic syndrome and obesity research. Original research, review, case reports, hypothesis formation, expert opinion and commentaries are all considered for publication. The manuscript management system is completely online and includes a very quick and fair peer-review system, which is all easy to use. Visit http://www.dovepress.com/testimonials.php to read real quotes from published authors. 